\title{
Forthcoming meetings convened by the Conference of European Statisticians
}

\author{
Second joint meeting on questions of statistics concerning engineering industries \\ and automation (Geneva, October 1988) \\ The meeting is convened jointly by the Conference of European Statisticians \\ and the ECE Working Party on Engineering Industries and Automation. In \\ particular, the meeting will be informed about work on international nomencla- \\ tures, and methods of collection and publication of data relating to engineering \\ industries. Various methodological aspects of statistics of these industries will \\ also be discussed, such as the selection of indicators to study industrial develop- \\ ment under both an economic and a technical perspective.
}

Work session on statistics of solid wastes (Geneva, November 1988)

The session is to prepare the revision of the draft ECE standard international classification of solid wastes. It will, inter alia, review the coverage of radioactive wastes, the breakdown of household and industrial wastes, and assess the scope and coverage of agricultural wastes.

Work session on statistics of air quality (Geneva, November 1988)

The main concern of the session will be to advance the revision of the draft ECE standard international classification of ambient air pollution. The revision will be guided by the experience gained in the compilation of "Environment Statistics in Europe and North America".

Working Party on transport statistics (Geneva, December 1988)

The Working Party is convened jointly by the Conference of European Statisticians and the Inland Transport Committee of ECE. It will discuss the development of internationally comparable standards, including methods of data 
collection and definitions concerning statistics on inland transport and road traffic accidents.

Meeting on statistics of education (Geneva, January 1989)

This meeting has been convened jointly with UNESCO to consider adult and out-of-school education statistics, education finance statistics, issues affecting international comparability, and methodological problems (including individual data systems, problems of longitudinal studies and problems in the use of sample surveys).

Consultation of the International Comparison Project (Vienna, January 1989)

The consultation will discuss the terms of the 1990 round of the European Comparison Programme, including the scope and shape of the comparison (classification systems, etc.), the possible introduction of new methods, and the organization of work.

Study Group on food and agricultural statistics in Europe (Geneva, February 1989)

The Study Group is convened jointly by the Conference of European Statisticians and the FAO/ECE Committee on Agricultural Problems. It will review national experiences in applying the European Handbook of Economic Accounts for Agriculture and other international recommendations, and will consider the general co-ordination of data collection and harmonization of international questoinnaires in the field of agricultural statistics.

\section{Meeting on human settlements statistics (Geneva, February 1989)}

The Conference has convened this meeting jointly with the ECE Committee on Housing, Building and Planning. The meeting will review the content and structure of the Annual Bulletin of Housing and Building Statistics for Europe, review the European Programme of Current Housing Statistics, study the possibility of extending the scope of the European Programme to cover the broader range of human settlements statistics, and exchange experience on recent developments in housing sample surveys.

Seminar on the relevance and importance of population and housing census data (Wiesbaden, Federal Republic of Germany, March 1989)

This seminar will be held in Wiesbaden at the invitation of the Government of the Federal Republic of Germany. The seminar will focus on the importance of 
population and housing census data in the 1990s. The following topics will be considered: (i) the value, importance and uses of censuses (including reviews of various benefits to society from censuses); (ii) servicing census markets with census products; (iii) prospects for replacing population and housing censuses either totally or partially by surveys and administrative registers; (iv) possibilities of taking improved or more cost-effective censuses; and (v) perceptions of the census by the public (including census confidentiality, publicity and respondent resistance).

The seminar is intended for both producers and users of census data. All participants must be accredited by the competent authorities of their country or intergovernmental organization. Additional information on the seminar may be obtained from national statistical offices in the ECE region or from the ECE secretariat.

Twenty-first session of the Working Party on electronic data processing (Geneva, February 1989)

The Working Party will discuss the impact of new processing techniques on the management and organization of statistical data processing and on the relationship between computer specialists and statisticians. It will also consider standards for statistical data interchange. Finally, the Working Party will review national reports on the use of EDP in Statistical offices, with particular reference to automated data bases.

\section{Meeting on classifications of environment statistics (Geneva, March 1989)}

The meeting is tentatively scheduled for the purpose of finalizing classifications of land use, water use and solid wastes. The meeting will not be held if preparatory work cannot be adequately concluded. 